Ecología espacial de una manada de pecarí de labios blancos (Tayassu pecari) en Belice, usando collares con GPS: desafios y resultados preliminares

\title{
Spatial ecology of a herd of white-lipped peccaries (Tayassu pecari) in Belize using GPS telemetry: challenges and preliminary results
}

\author{
Maarten P. G. Hofman ${ }^{1,2 *}$, Johannes Signer ${ }^{1}$, Matthew W. Hayward² and Niko Balkenhol ${ }^{1}$
}

\begin{abstract}
'Department of Wildlife Sciences, University of Göttingen. Büsgenweg 3, 37073 Göttingen, Germany. Email: mhofman1@gwdg.de (MPGH), jsigner@gwdg.de (JS) niko.balkenhol@forst.uni-goettingen.de (NB).

${ }^{2}$ School of the Environment, Natural Resources and Geography, Bangor University. Thoday Building, Deiniol Road, Gwynedd LL57 2UW, UK. Email: m.hayward@bangor.ac.uk (MWH).

* Corresponding author
\end{abstract}

\begin{abstract}
The Maya Mountains are a heavily forested mountain range in Belize and Guatemala supporting high levels of biodiversity. Due to environmental degradation around the range, it is in danger of becoming isolated from the largest contiguous forest in Central America. Forest connectivity in the area is vital for white-lipped peccaries. These social ungulates roam in herds of up to 300 individuals and need large forested areas to sustain populations. The species has not previously been studied in Belize and its distribution, population size, herd dynamics and movement patterns are unknown for the country. We aimed to estimate home range size and investigate movement patterns of the species in southern Belize. We present a preliminary 4-month data set from a herd of ca. 60 animals tracked by an individual fitted with a GPS satellite collar. We evaluated collar performance, habitat preference and movement characteristics, and estimated home range size using a semi-variogram approach, suited for sparse and irregular data. Collar performance was poor, with $38 \%$ of the data not reaching the satellite, and a GPS fix success rate of $11.6 \%$ for the data that did reach the satellite. The semivariogram home range size was $55.2 \mathrm{~km}^{2}$. We observed a maximum daily movement distance of $3.8 \mathrm{~km}$, and a preferential use of forest habitat over shrubland, savannah and cropland. We calculated a density of $1.09 \mathrm{ind} / \mathrm{km}^{2}$ and make an informed guess of close to 100 herds in the broad-leaf forests of the Maya Mountains. Our study highlights some of the challenges faced when collaring white-lipped peccaries, as well as the performance of GPS-collars in tropical forests. It also provides a first glimpse of the home range and movement behaviour of white-lipped peccaries in Belize.
\end{abstract}

Las Montañas Maya son una cadena montañosa densamente forestada situada entre Belice y Guatemala que presenta altos niveles de biodiversidad. La degradación medioambiental amenaza con dejarla aislada del gran bosque Centro Americano contiguo. El pecarí de labios blancos es un ungulado social que viaja en manadas de hasta 300 individuos y que necesita grandes extensiones forestales para mantener sus poblaciones, por lo que la conectividad entre bosques es esencial para la especie. No existen estudios sobre esta especie en Belice, de manera que su distribución, tamaño de población y patrones de movimiento son desconocidos para este país. El objetivo del estudio fue de estimar el ámbito hogareño y de investigar patrones de movimiento de esta especie en el sur de Belice. Este estudio presenta datos preliminares de una manda de aproximadamente 60 individuos obtenidos a partir de un individuo que fue marcado con un collar equipado con GPS. Se investigó el rendimiento del collar, uso preferencial de hábitat y patrones de movimiento, y se estimó el ámbito hogareños usando un análisis de semivariograma. El rendimiento del collar fue pobre puesto que un $38 \%$ de los datos no alcanzaron el satélite, mientras que la tasa de éxito de adquisición de localizaciones de las que si alcanzaron el satélite fue del $11.6 \%$. El ámbito hogareños fue de $55.2 \mathrm{~km}^{2}$. La distancia máxima de movimiento diario observada fue de $3.8 \mathrm{~km}$ y se constató un uso preferencial de hábitat forestal contra el matorral, sabana o tierras de cultivo. Se calculó una densidad de 1.09 individuos $/ \mathrm{km}^{2}$ y se conjetura que hay, aproximadamente, unas cien manadas habitando los bosques caducifolios de las Montañas Maya. Nuestro estudio detalla las dificultades que entraña marcar con collares al pecarí de labios blancos así como el rendimiento de los collares en los bosques tropicales. Asimismo, también proporciona una información preliminar sobre el ámbito hogareño y el comportamiento del movimiento del pecarí de labios blancos en Belice.

Key words: Bladen Nature Reserve; fix success rate; fragmentation; GPS-collar; habitat preference; Maya Mountains; sedation; semivariogram; trapping; tropical forest.

๑) 2016 Asociación Mexicana de Mastozoología, www.mastozoologiamexicana.org 


\section{Introduction}

The Maya Mountains are a heavily forested mountain range in Belize and Guatemala, and form the southernmost part of La Selva Maya, the largest tropical forest block in the Americas after the Amazon (Radachowsky et al. 2012; Briggs et al. 2013). The diverse geology accounts for a range of different soil types and a dramatic topography, which result in a multitude of microhabitats. These characteristics, combined with tropical rainfall regimes, yield some of the highest levels of biodiversity in the region (Brewer and Webb 2002; Dourson 2012). The Maya Mountains are also part of the Mesoamerican Biological Corridor, a regional initiative to conserve connectivity among forests in Central America (Herrera 2003). On a national level, the Maya Mountains cover $22.2 \%$ of Belize's land mass, forming the largest contiguous forest in the country, and are regarded as a Key Biodiversity Area (Meerman 2007). They are estimated to provide up to 1 billion USD worth of ecosystem services to the people of Belize (Hammond et al. 2011), and constitute one of biggest resources in the country for local livelihoods, forestry and eco/agritourism (Briggs et al. 2013). Despite the fact that most of the Belizean side of the mountain range consists of protected areas of various legal categories (Figure 1), increasing industrial and small scale clear-cutting have severed the connections between the Maya Mountains and the forests to the north in both Guatemala and Belize. Consequently, the Maya Mountains are becoming increasingly isolated (Briggs et al. 2013).

The white-lipped peccary Tayassu pecari (Link 1795) is often one of the first mammals to disappear with increasing forest fragmentation (Sowls 1997; Moreno and Meyer 2014). Whitelipped peccaries are gregarious ungulates travelling in herds of 10 to 300 individuals (Sowls 1997; Altrichter et al. 2012), and although they are known to occur in mosaic landscapes, they are regarded as typical forest dwellers (Fragoso 1999; Reyna-Hurtado and Tanner 2005; Keuroghlian and Eaton 2008; Desbiez et al. 2009; Tobler et al. 2009; Reyna-Hurtado et al. 2009). Due to the large herd size, they need to move frequently among different feeding spots, and in the process cover large distances through the forest. Home range sizes throughout the species' range vary substantially, ranging from 20 to $200 \mathrm{~km}^{2}$ (Fragoso 2004; Keuroghlian et al. 2004; Reyna-Hurtado et al. 2009; de Almeida Jácomo et al. 2013). This variation reflects the environmental variability over the range of the species and illustrates its ability to cope with different conditions. Nevertheless, this flexibility seems to consist mainly of varying herd size (Fragoso 2004) or splitting up in subherds (e.g.Keuroghlian et al. 2004), rather than of changing habitat preferences. Thus, despite their ability to deal with different environmental conditions, white-lipped peccaries always depend on intact forest habitats of sufficient size and connectivity, rendering them highly susceptible to forest conversion and fragmentation. The Maya Mountains are assumed to offer continuous habitat and are expected to be home to several herds of white-lipped peccaries. However, no studies have been conducted on this species in Belize; their distribution, population size, herd dynamics and movement patterns are unknown for the country. The rugged topography of the Maya Mountains might render some parts of the forest unsuitable, and species-specific connectivity among suitable forest areas remains unstudied.

Here, we provide a preliminary report on data gathered from a herd of $c a .60$ by tracking a single white-lipped peccary that was GPS-collared to investigate its home range and movement patterns in the Bladen Nature Reserve, southern Belize. We assume that the location of the GPScollared individual adequately represents the area used by its herd at the same point in time, because in many gregarious species the tendency of individuals to always move with the herd is very strong. In fact, this tendency has been used for management purposes in conservation. For example, Taylor and Katahira (1988) used the 'Judas goat' approach to help eradicate feral goats (Capra hircus) on the Hawaiian Islands, and Campbell et al. (2004) and Cruz et al. (2009) used it for similar reasons on the Galápagos Islands. That is, goats fitted with a radio-collars (the 
Judas goats) were used to get information about the location of an entire herd of feral goats. All members of the discovered herds were killed, with the exception of the Judas goats, which would go on to find another herd, where the same scenario was repeated. A similarly strong herding tendency was described by Byers and Bekoff (1981) for collared peccaries (Pecari tajacu), and we can confirm such cohesiveness for white-lipped peccaries too based on camera trap footage from within our study area (M. Hofman, unpublished data) and evidence from several earlier studies on the species elsewhere (Keuroghlian et al. 2004; Reyna-Hurtado et al. 2009). For example, in neighbouring Calakmul, Mexico, collared animals were always seen with their respective herds for more than 700 observations (Reyna-Hurtado pers. comm.). Hence, the collaring of additional individuals from the same herd would not necessarily yield additional information on home range and movement patterns of that herd.

\section{Methods}

Study area. The Bladen Nature Reserve (BNR; 16.48, -88.88) is a strictly protected area (IUCN Cat. la) gazetted in 1990, covering about $40.5 \mathrm{~km}^{2}$ of the southern Maya Mountains, and centred around the watershed of the Bladen branch of the Monkey River. Since 2008, the reserve has been managed by a local conservation NGO, the Ya'axché Conservation Trust, under mandate of the Belize Forest Department. Vegetation is almost exclusively lowland and submontane broad-leaf wet forest with relatively open understorey and a canopy height of 20-30 m (Iremonger et al. 1995). Lowland areas are

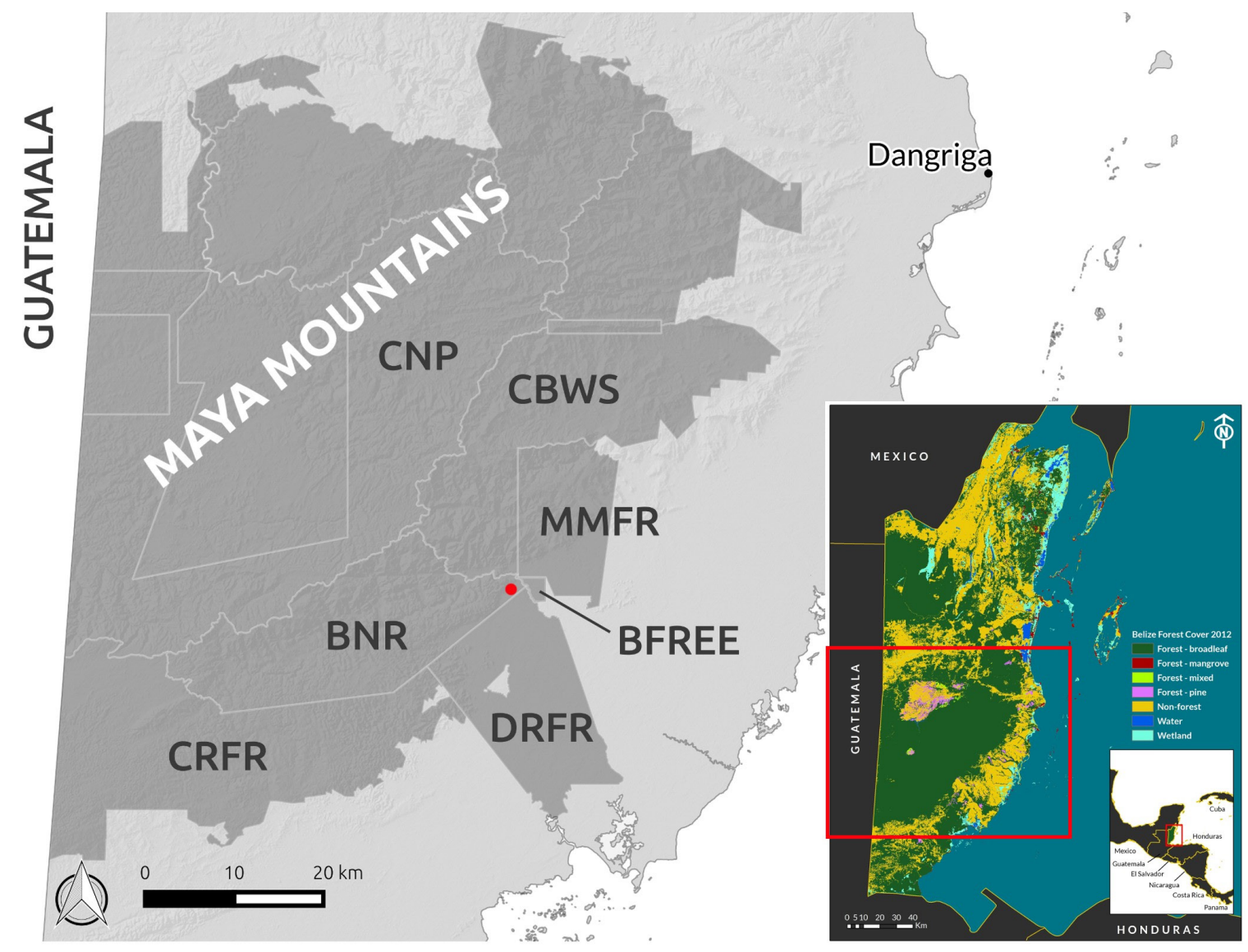

Figure 1. Location of Belize and the Maya Mountains. The protected areas of the Maya Mountains (as delineated by Briggs et al. 2013) are shaded grey and the trapping area is indicated by a red dot. Protected areas that are directly relevant to the study area are annotated. BFREE: Belize Foundation for Research and Environmental Education; BNR: Bladen Nature Reserve; CNP: Chiquibul National Park; CBWS: Cockscomb Basin Wildlife Sanctuary; CRFR: Columbia River Forest Reserve; DRFR; Deep River Forest Reserve; MMFR: Maya Mountain Forest Reserve. 
characterised by abundant Astrocaryum mexicanum and Attalea cohune palms, while tree diversity is dominated by the Fabaceae, Rubiaceae, Sapotaceae and Lauraceae families (Iremonger et al. 1995; Brewer and Webb 2002; Stott 2014). The protected area also contains a sliver of seasonally inundated lowland savannah in its far eastern tip, and a pocket of pine forest. Due to its inaccessible terrain with steep slopes and extremely narrow valleys, the area holds some of the most undisturbed forests of Belize and is very high in biodiversity (Brewer and Webb 2002; Dourson 2012; Dourson 2012), with ongoing species discoveries (Polhemus and Carrie, 2013; Thompson and Dourson 2013). Its elevation spans from 30 to $1050 \mathrm{~m}$, some of the highest areas in Belize. It is one of the wettest areas in Belize receiving an average annual rainfall between 2,500 and >3,000 mm, with $85 \%$ falling between mid-May and the end of November (Brewer and Webb 2002), and an annual average temperature of around $26^{\circ} \mathrm{C}$. The area has a distinct dry season from March to mid-May. It is bordered by six other protected areas with a lower protection status, which are equally likely to be used by white-lipped peccaries, given the contiguous habitat type and expected ranging behaviour of the species (Figure 1, 3). The nearest human settlements are Medina Bank ( 300 inhabitants, mostly Q'eqch'i Maya) and Trio Village ( 3,000 inhabitants, mostly Q'eqch'i Maya and Mestizos from Guatemalan origin), and their agricultural areas border the Maya Mountain Forest Reserve and Belize Foundation for Research and Environmental Education. BNR is separated from a two-lane highway to the south-east by a five $\mathrm{km}$ wide stretch of savannah and lowland broadleaf forest, mostly within the Columbia and Deep River Forest Reserves.

White-lipped peccaries are occasionally spotted by Ya'axché field staff throughout the reserve, with estimated herd sizes between 60 and 100 individuals, but it has been unclear how many herds roam the area and whether or not they interact. Anecdotal reports from farmers and hunters suggest a declining population over the last 10 years in southern Belize. There are no reports about crop raiding by white-lipped peccaries in southern Belize and we assume that the animals in the research area have little or no contact with humans, with the exception of enforcement personnel and visiting researchers. Hunting pressure in eastern BNR is expected to be low due to long-term intensive enforcement activities in the area. In other parts of the reserve and in the surrounding areas, hunting pressure is expected to be higher (M. Hofman, pers. obs.).

Trapping. White-lipped peccaries have been trapped either by tracking or ambushing freerange animals (Fragoso 1998; Fuller et al. 2002; Reyna-Hurtado et al. 2009), or by using baited box and/or corral traps (Sowls 1997; Carrillo et al. 2002; Keuroghlian et al. 2004; de Almeida Jácomo et al. 2013; C. Richard-Hansen, pers. comm.). We used one box trap $(1 \times 1 \times 2 \mathrm{~m})$ and one corral trap $(\varnothing$ ca. $6 \mathrm{~m}, 1.5 \mathrm{~m}$ high, with handling compartment), spaced about $2.5 \mathrm{~km}$ apart, each in the proximity of a creek showing signs of peccary activity. The traps were deployed in July and August 2014, during the peak rainy season in southern Belize. Camera traps had indicated previous occasional presence at the corral trap site during two previous years. The traps were baited with various fruits; as well as cassava (Manihot esculenta) and cocoyam (Xanthosoma spp.) roots. Because only one collar was available, one adult female of appropriate size (estimated $>25 \mathrm{~kg}$ ) was selected and isolated from the captured individuals, using recommended pig handling tools, including a confined restraining compartment, board and snare (Defra 2003; Grandin 2013). With the aim of minimizing the duration of the process, we did not use sedation. All animal trapping and handling followed the guidelines of the American Society of Mammalogists (Sikes and Gannon 2011), and was permitted by the Belize Forest Department [Permit no. CD/60/3/14(37)]. The individual was fitted with a Telonics TGW-4570-3 GEN4 GPS/Iridium collar (Telonics, Mesa AZ, USA). The collar was programmed to start a fix attempt every three hours, theoretically yielding eight locations per day. If no GPS fix was obtained after 180 seconds, the fix attempt was aborted and classified as unsuccessful. Data were scheduled to transfer to the satellite every two days. Data remained on the sending list for 10 days, then would remain stored on-board but would not be sent. 
Home range size and movements. We used the semi-variance approach developed by Fleming et al. (2014) to detect whether the herd displayed home ranging behaviour, and to estimate the home range size. The approach makes use of the auto-correlated nature of tracking data to investigate processes that occur over different time scales (e. g. foraging vs. migration or dispersal). The semi-variogram measures the distance between two relocations as a function of the time lag between them, and calculates the variability of distances among all relocation pairs with the same time lag. When an animal displays home ranging behaviour, increasing the time lag between relocations leads to an asymptote in distance covered, because animals would not usually travel further than their home range diameter, even when given more time. Hence, the approach can be used both to detect home range behaviour and to estimate home range size. Since movement distances are averaged within time lags, the approach is robust in the face of irregular and sparse relocation data, i.e. varying fix intervals and long data gaps (Fleming et al. (2014)).

We used the ctmm package (Fleming and Calabrese 2015) for the $R$ statistical environment ( $R$ Development Core Team 2010) for all semi-variance calculations. Following Fleming et al. (2014), we calculated the empirical variogram, and selected the best fitting Semi-Variance Function (SVF) from a set comprised of i) a null-model (Brownian motion, i. e. random, undirected movement), ii) an Ornstein-Uhlenbeck motion model (OU - Brownian Motion within a home range), and iii) an OrnsteinUhlenbeck motion model with foraging included (OUF), i. e. assuming regular Brownian motion (while foraging) on a very short time scale, and Ornstein-Uhlenbeck motion on longer time scales. We used the Akaike Information Criterion corrected for small sample size (AICc) to select the best model.

Additionally, to allow comparisons with previous home range estimates for the species, we used the rhr package ( $r$ Signer and Balkenhol 2015) in R to estimate 50, 95, 99 and $100 \%$ Minimum Convex Polygon (MCP) home ranges, as well as 50, 95, 99 and $100 \%$ isopleths from a kernel density home range estimate (KDE) with bandwidth set to the reference bandwidth. From the latter calculations, a core home range area was estimated using the method of Seaman and Powell (1990) as provided in the rhr package (Supporting Information 1). To investigate movement rates, we calculated step characteristics using the rhr package and summarized step lengths to indicate movement distances over three time spans: 6, 12, and 24 hours.

Habitat preference. To investigate habitat selection within home ranges (i. e. thirdorder habitat selection; Johnson 1980), we used the most recent land use/land cover map available in vector format based on 30m-resolution Landsat data, specifically for Belize from the Belize Environmental Resource Data System of Belize (BERDS 2005), representing the 2011 situation with 18 land use/land cover classes. We considered the proportion of each land use/land cover class within the 100\% MCP as available, and the proportion of relocations in each class as the proportion of habitat used. We tested for differences between available and used with a $x^{2}$-test. Additionally, we calculated the Jacobs index (Jacobs 1974) to detect which specific classes were used more often than expected from their availability in the landscape. The Jacobs index is a modified version of Ivlev's electivity index (Ivlev 1961) that takes into account the relative abundance of a resource when identifying an organism's resource preferences (Jacobs 1974). It is calculated as $D=(r-p)$ $/(r+p-2 r p)$, where $r$ is the proportion of habitat used and $p$ is the proportional habitat availability. $D$ varies from -1 under strong avoidance to +1 under strong habitat preference. Values close to 0 indicate that the habitat is used in proportion to its availability. 


\section{Results}

Trapping success. On April 22 $2^{\text {nd }}, 2015$, we trapped 12 individuals from a herd of an estimated 60 in the corral trap. The individual selected for collar deployment was an adult female, estimated to weigh just over $25 \mathrm{~kg}$. Fitting the collar took ca. five minutes, after which the animal was released from the handling compartment to join the others in the corral. Camera trap footage showed the collared female among the rest of the herd less than four hours after the trapping event, and with its young, both in good health, two weeks later.

GPS fix rate and data transfer. We report here on data collected between 22 April and 22 August 2015, i. e. 121 days of collar deployment. Data for ca. 47 days did not transfer to the satellite, meaning that $38.7 \%$ of the time we did not know whether a fix attempt had been successful, and where the animal was located. The average length of such data gaps was 6.7 ( \pm 3.0 SD) days, with a maximum of 12 days. From all the fix attempts that were transmitted to the satellite $(n=593)$, only $11.6 \%$ were successful, thus yielding a total of 69 GPS fixes over the study period.

Home range. The empirical semi-variogram was best approximated by the semivariance function representing Ornstein-Uhlenbeck motion including foraging (OUF; $2221.51 \mathrm{AICc}$ ), and thus showed evidence for home ranging behaviour over the four-month monitoring period (Figure 2). Only on very short time scales did the animal display random, undirected movement $(2.53$ hours, $\mathrm{Cl} 0.92,6.91)$ indicative of foraging. The $\mathrm{OU}$ and $\mathrm{BM}$ models followed with $\triangle \mathrm{AICC} 8.11$ and 1760.48 respectively.

The estimated home range size was $55.2 \mathrm{~km}^{2}(\mathrm{Cl} 34.09,81.32)$ which the animals could cover in 3.66 days ( $\mathrm{Cl} 1.70,7.89$; Figure 3 ). The $95 \% \mathrm{MCP}$ home range estimate was less than half that of the $95 \% \mathrm{KDE}$ isopleth, while the core area estimate based on the KDE was closer to the $95 \%$ MCP (Table 1).

Movement. Mean distances covered during fix intervals of six, 12 and 24 hours were 190, 910 and $1181 \mathrm{~m}$ respectively, while daily distances covered between subsequent fixes with multi-day fix intervals averaged around $900 \mathrm{~m}$ (Table 2). The maximum distance covered during fix intervals of up to one day was $2,380 \mathrm{~m}$. For fix intervals longer than one day, the maximum observed speed was 3,788 m/day. Over all fix intervals, the maximum movement speed calculated was $270 \mathrm{~m} / \mathrm{h}$.

Habitat preference. Comparing the proportion of land use/land cover types for the relocations with the proportion of these classes in the $100 \% \mathrm{MCP}$ area, a $X^{2}$-test showed significant difference between use and availability $\left(X^{2}=15.133\right.$ and $P<0.001$ based on 2000 Monte Carlo replicates).

Jacobs $\mathrm{D}$ indicated a preference for broadleaf forest and a slight avoidance of shrubland (Table 3). Since no relocations were recorded in savannah and agricultural lands, the $D$ index indicates total avoidance (-1.00). Note that we could not calculate significance levels for preferences of individual land cover classes, because our sample size of one does not allow us to calculate the relevant test statistics.

\section{Discussion}

Home range, density and population size. Even though white-lipped peccaries have been considered nomadic or migratory in early studies (Kiltie and Terborgh 1983; Bodmer 1990), the current consensus is that they use well-defined home ranges that are large enough to encompass seasonal or multiannual movements (Fragoso 2004; 


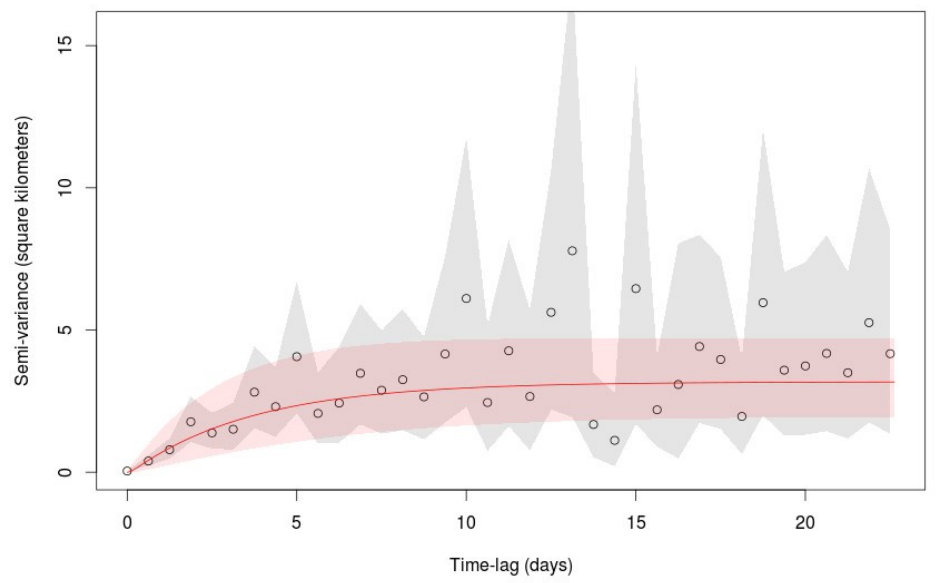

Figure 2. Semi-variogram of all GPS fixes of a single white-lipped peccary in southern Belize $(n=69)$. Circles represent the estimated semi-variance for each time-lag, with $95 \%$ confidence intervals estimated from the standard error of the mean semi-variance shaded light grey. The fitted OUF model (see text) is shown as a red solid line with its $95 \%$ confidence intervals estimated from the standard error of the best fit shaded light red.

Keuroghlian et al. 2004; Reyna-Hurtado et al. 2009; de Almeida Jácomo et al. 2013). All our home range estimates fall within the range sizes reported for white-lipped peccaries from areas under various disturbance and rainfall regimes in Brazil, Costa Rica, and Mexico (Fragoso 1998, 2004; Carrillo et al. 2002; Keuroghlian et al. 2004; Reyna-Hurtado et al. 2009; de Almeida Jácomo et al. 2013). However, the time span covered by our estimates is four months for a single herd, whereas the other estimates cover multiple herds, each of which was tracked for a period of three months to more than one year. Despite the short time span, our data covers the end of the 2015 dry season and the beginning and peak of the wet season of the same year, and it remains to be seen whether our home range estimates will shift or expand during the transition into the 2016 dry season, until the collar drops off in May 2016. However, although the semi-variogram indicated home ranging behaviour, it is impossible to say whether our location data adequately represent the entire home range, given the numerous gaps in the data. For example, we suspect that the dense canopy in rugged terrain may more severely affect GPS fix success rate and satellite data transfer than relatively flat terrain, which would cause an underestimate of space-use in the more rugged areas.

Table 1. Home range size estimates for a single white-lipped peccary herd in southern Belize across different levels.

\begin{tabular}{lrc}
\hline & Level (\%) & Area $\left(\mathbf{k m}^{2}\right)$ \\
\hline & 50.00 & 7.13 \\
MCP* $^{*}$ & 95.00 & 33.48 \\
& 99.00 & 33.58 \\
& 100.00 & 33.59 \\
$\mathrm{KDE}^{* *}$ & 50.00 & 17.67 \\
& 95.00 & 69.38 \\
Core area & 99.00 & 96.71 \\
Semi-variogram & 79.80 & 41.01 \\
\hline \multirow{2}{*}{ *Minimum Convex Polygon } & $\mathrm{NA}$ & 55.20 \\
** Kernel Density Estimate & &
\end{tabular}



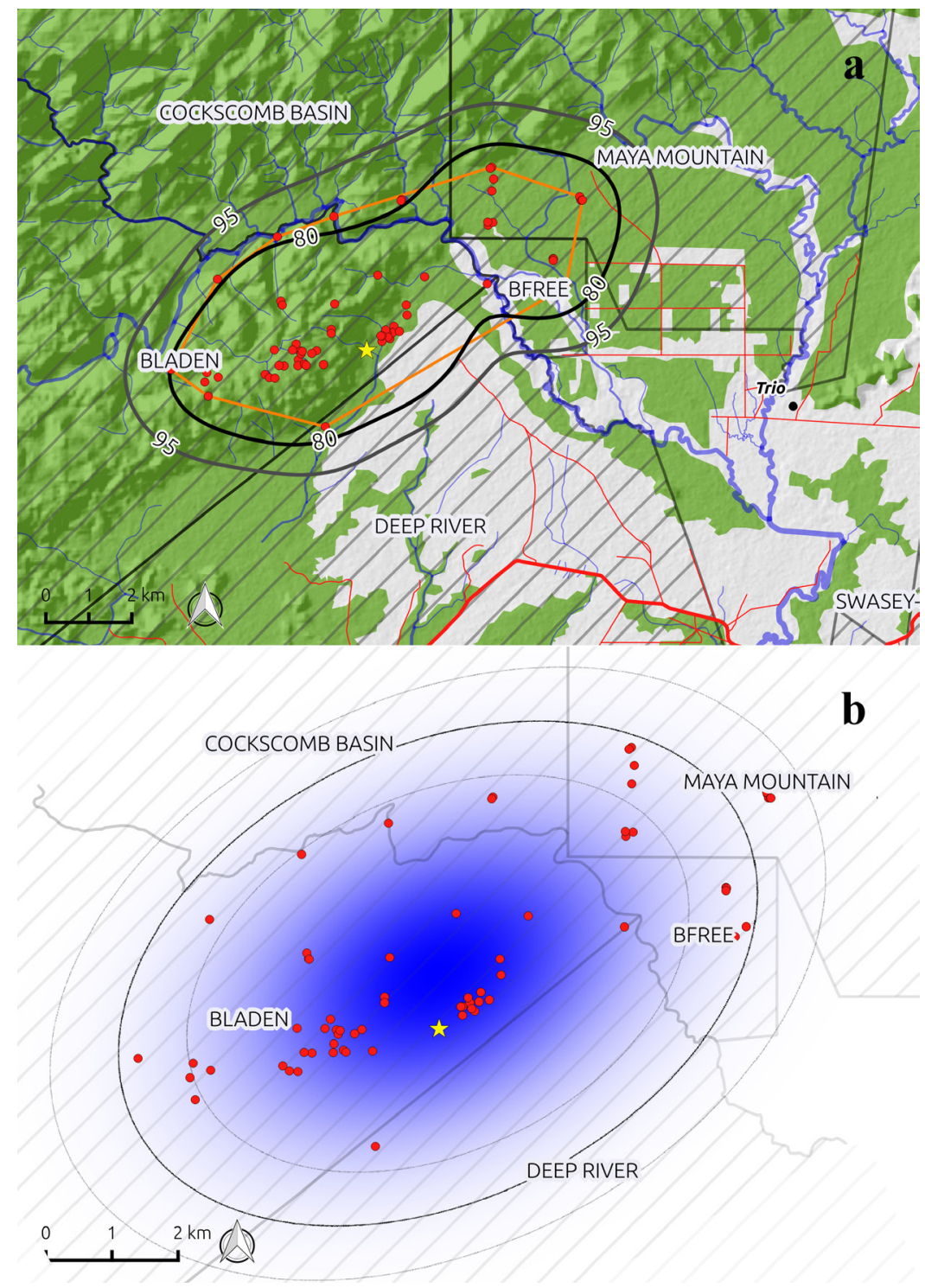

Figure 3. Spatial representation of the home range estimates for a single white-lipped peccary herd in southern Belize. a) $95 \%$ Kernel Density Estimate home range (dark grey line), Core area (80 \% KDE - black line) and $100 \%$ MCP home range (orange line) over the relocations (red dots), rivers (blue) and roads (red lines). Black dots represent villages, the yellow star is the corral trap location. Forest cover is shaded green, grey shaded areas are non-forest (savannah, shrubs and agricultural lands), and grey diagonally line-filled areas with straight black boundaries are protected areas. b) Semi-variogram home range estimate (black ellipse) with $95 \%$ confidence interval (grey ellipses) and utilisation density (blue shading).

Nonetheless, within the home range estimated thus far, our habitat preference results agree with the preference for forested areas that is well-known for the species. Given the low availability of agricultural lands inside the MCP area and the limited number of relocations, the total avoidance of agricultural lands remains uncertain. With about $12.5 \%$ of the home range covered by savannah, it is remarkable that no relocations were observed there, while almost $5 \%$ of the relocations were located in shrubland, which was available at half the rate as savannah. This could be explained by i) shrubland providing better cover or food and ii) the patchy spatial configuration of shrubland throughout the forest making movement through these patches more likely than through the one continuous patch of savannah south of the forested areas. However, we emphasize that due to a sample size of one herd, significance testing of preference for specific habitats was not possible. 
Table 2. White-lipped peccary step length statistics for different time intervals between GPS fixes

\begin{tabular}{lcrrr}
\hline & $\mathbf{n}$ & \multicolumn{1}{c}{ Mean (SD) } & Median & \multicolumn{1}{c}{ Maximum } \\
\hline$\Delta \mathrm{t}<6 \mathrm{hrs}$ & 17 & $190( \pm 208)$ & 119 & 802 \\
$6 \mathrm{hrs} \geq \Delta \mathrm{t}<12 \mathrm{hrs}$ & 11 & $910( \pm 814)$ & 882 & 2380 \\
$12 \mathrm{hrs} \geq \Delta \mathrm{t}<24 \mathrm{hrs}$ & 13 & $1181( \pm 786)$ & 1074 & 2260 \\
$\Delta \mathrm{t} \geq 24 \mathrm{hrs}^{*}$ & 27 & $900( \pm 806)$ & 792 & 3788 \\
\hline
\end{tabular}

${ }^{*}$ statistics per day

Due to its robustness with sparse data, we consider the semi-variogram estimate the most accurate for our data set. Using the home range size estimate (and confidence intervals) of this approach and our estimated number of individuals in the herd ( $n=$ $60)$, we would obtain a density of $1.09(\mathrm{Cl} 0.74,1.76) \mathrm{ind} / \mathrm{km}^{2}$. If we i) extrapolate these home range and density estimates to other herds in the Maya Mountains (as delineated by Briggs et al. 2013), and ii) assume that all the broad-leaf forest habitats in the Maya Mountains are suitable for white-lipped peccaries, we estimate $99(\mathrm{Cl} 67,160)$ herds roaming the area, and a population size of 5,917 individuals $(\mathrm{Cl} 4017,9582)$. Clearly, the assumptions for these estimates are untested and the estimates are therefore associated with very high uncertainty; we include them here in the discussion for indicative purposes only. Our density estimate of $1.09 \mathrm{ind} / \mathrm{km}^{2}$ is in the lower half of the range of estimates from the Argentinian Gran Chaco (1.02 ind $/ \mathrm{km}^{2}$ Altrichter 2005), the Brazilian Cerrado (2.99 ind $/ \mathrm{km}^{2}$ Desbiez et al. 2010) and southern Brazil (4.5 ind $/ \mathrm{km}^{2}$ Keuroghlian et al. 2004), but still considerably higher than in the Calakmul Biosphere Reserve in Mexico (0.43 ind $/ \mathrm{km}^{2}$ Reyna-Hurtado et al. 2009), which is geographically closest to our study area. However, all of these areas are drier and/or less forested than our study area, which is expected to influence group size and density. For example, the high density in southern Brazil might be due to a crowding effect in the fragmented forests. We expect to have overestimated population size, because not all broad-leaf forests in the Maya Mountains are expected to be used by the species, and hunting pressure in the herd's home range is expected to be lower than in most other parts of the area. Nevertheless, the estimates suggest that the Maya Mountains can potentially harbour a large number of while-lipped peccaries, warranting greater research emphasis and conservation incentives on the species in this region.

Collar performance. The numerous reports of successfully deployed GPS collars in different environmental settings convincingly illustrate the potential that this equipment holds for obtaining large quantities of high quality data in wildlife research (Edenius 1996; Eriksen et al. 2011; Martins et al. 2011; Harju et al. 2013; Krofel et al. 2013). However, the use of GPS collars often comes with unforeseen technical or data quality issues (Sager-Fradkin et al. 2007; Matthews et al. 2013). In particular, studies from tropical forests report imprecise locations or low GPS fix success rate (Phillips et al. 1998; Blake et al. 2001; Lizcano and Cavelier 2004; Coelho et al. 2007; Barlow 2009; Hwang et al. 2010). While we anticipated that the dense forest and steep terrain in our study area would pose a challenge for any telemetry-based research, we opted for GPS collars because i) we wanted to obtain detailed information on movement patterns to parametrize a mathematical model for simulating potential movement paths of peccaries in Belize, and ii) the cost of obtaining a limited number of GPS collars was estimated less than the personnel and equipment costs for running a large camera trap grid or transect network in the inaccessible area. Unfortunately, the fix success rate of $11.6 \%$ was much lower than expected from the literature, even for the 
given environmental conditions. However, collar malfunction cannot be excluded as a possible explanation. For logistical reasons, we could not perform collar tests in the field prior to deployment, but we stress that this should in fact be standard practice. The poor performance of one collar cannot be used to draw general conclusions about the viability of GPS collars in rugged tropical environments, but we suggest that a review on the usefulness of GPS collars specifically in such environments is needed to help researchers determine a priori the potential in their area. Nonetheless, we are confident that the data gathered during this study outperforms data collection using regular VHF collars in our area and for our highly mobile target species, both in terms of quantity and quality of locations obtained.

Movement. Movement data of high temporal resolution has been, and remains, difficult to obtain for white-lipped peccaries, and hence movement distances of white-lipped peccaries have mostly been described qualitatively in terms of home range behaviour, migration and/or nomadism (Sowls 1997). In this study, the herd of the tagged white-lipped peccary seemed to move about $1 \mathrm{~km}$ per day on average, but did at times travel at $270 \mathrm{~m} / \mathrm{h}$ and covered up to 3,788 $\mathrm{m}$ per day, which enabled the herd to traverse its home range in two to eight days. Due to our frequent sampling gaps however, our estimates likely underestimate the mobility of the species in our study area. For comparison, Fragoso (1998) reported distances from 1200 to 2600 $\mathrm{m}$ between VHF relocations of unknown time intervals, while Reyna-Hurtado et al. (2009) mentioned a travel speed of up to $3,000 \mathrm{~m} / \mathrm{h}$, traversing seasonal home ranges in one-day time intervals.

Based on observations elsewhere in Central and South America (Carrillo et al. 2002; Tobler et al. 2009; Moreira-Ramírez et al. 2015), we expected white-lipped peccary activity to peak during mid-morning and mid-afternoon. However, from our movement data (i. e. speed and distance measures), we were unable to detect any clear diurnal activity patterns (see Appendix 1). We attribute this to the poor fix success rate of the collar. The fix success rate is lowest during the most active periods of the day (Figure 4), leading to a lack of information on movement distance and speed during these periods. This suggests that the behaviour of the animal is potentially an important factor influencing the success of our GPS collar, in line with previous findings ( $D^{\prime}$ Eon and Delparte 2005). The downward trend in fix success rate from the onset of the high activity period also suggests that time since the last successful fix is inversely correlated to the probability of obtaining a successful subsequent fix. The time lag between fix attempts has been found to negatively affect fix success rate in previous studies (Moen et al. 2001; Cain et al. 2005).

Notes on behaviour. During the first six months, the animals visited the trap sites a total of five times with an average of 44.4 ( \pm 51.9 SD) days in between. In the next two months, visit frequency increased, with an average of 11 ( \pm 11.9 SD) days between subsequent visits. Note that the coefficient of variation in both cases is greater than one, indicating the unpredictability in time of the trap site visits. This visit frequency was generally lower than in Manu National Park in the upper Amazon basin in Peru, where white-lipped peccaries passed by the same observation site every 4.25 days in the dry season, and every 14.5 days in the wet season (Kiltie and Terborgh 1983). It is unclear whether this difference in visit frequency would be due to differences in food availability, wariness of human presence, or other factors. Other researchers have found similar time spans for the animals to increase trap visit frequency (three months to one year; C. Richard-Hansen pers. comm.). 


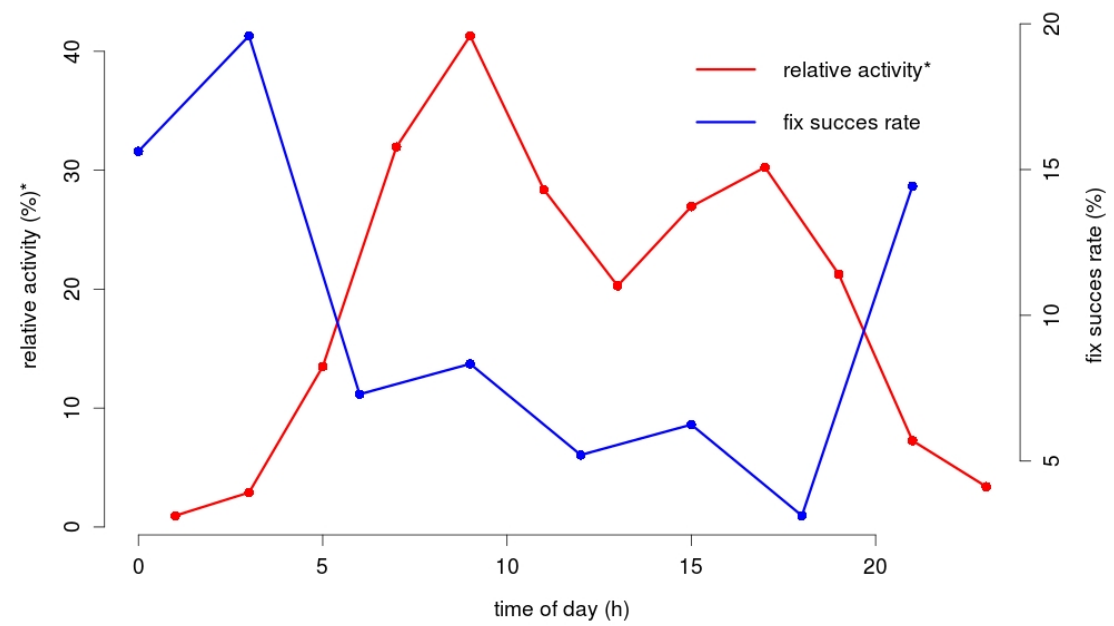

Figure 4. Fix success rate (\%) was very low in general, but especially so during expected high activity peaks. * relative activity was calculated as the mean relative activity from the datasets presented in Carrillo et al. (2002), Tobler et al. (2009) and Moreira-Ramírez et al. (2015).

White-lipped peccaries have been reported in some cases to engage in aggressive behaviour towards a threat (Sowls 1997), but we observed no direct attacks from the animals inside or outside the corral. Four of the trapped animals escaped upon our arrival as they managed to jump the fence using each other's backs as steps, while the remaining eight animals stood their ground and displayed a circular defence formation in the centre of the corral, in agreement with observations by Nietschmann (1972). Once the selected animal was isolated in the handling compartment out of view of the others, it was secured in place and let itself be handled without resistance.

\section{Conclusions and recommendations}

To our knowledge, white-lipped peccaries have so far been fitted with VHF-based radio-telemetry collars only, and no studies using GPS-collared white-lipped peccaries have been published. However such studies are being conducted in French Guyana, the Brazilian Pantanal and Mexico (C. Richard-Hansen pers. comm., A. Keuroghlian and R. Reyna-Hurtado, pers. comm.).

Our study illustrates some important challenges faced in trapping white-lipped peccaries and the use of GPS collars in dense tropical forests on rugged terrain. First, the time between the installation of the traps and the trapping success was considerably longer than anticipated. Second, collar performance was very poor in

Table 3. Habitat preference of a single white-lipped peccary herd in southern Belize

\begin{tabular}{lrrr}
\hline \hline & \multicolumn{1}{c}{ Available* $^{*}$} & \multicolumn{1}{c}{ Used } & \multicolumn{1}{c}{ Dt } \\
\hline Agriculture & $0.69 \%$ & $0.00 \%$ & -1.00 \\
Broad-leaf forest & $80.03 \%$ & $95.65 \%$ & 0.69 \\
Savannah & $12.54 \%$ & $0.00 \%$ & -1.00 \\
Shrubs & $6.74 \%$ & $4.35 \%$ & -0.23 \\
\hline
\end{tabular}

* Proportion of land use/land cover classes available within the $100 \%$ MCP home range

** Proportion of the relocations in each class

† Jacobs index 
our area, presumably due to animal behaviour, canopy cover and terrain conditions. Recent implementations of the quick fix pseudo-ranging (QFP) system in terrestrial applications could improve the performance (Tomkiewicz et al. 2010). Third, even though we found that collaring without sedation is possible, we have no information on the animal's stress levels while being handled other than the observation that the animal let itself be handled easily once isolated. Nogueira et al. (2015) simulated a hunting situation on captive white-lipped peccaries using a similar trapping setup as was used in this study. They found that the psychological negative effect (i.e. increased wariness) of the trapping event lasted no longer than eight days. However, the approach also has the disadvantage of not allowing for collecting body measurements or blood samples. For these reasons, we recommend using sedation when possible.

Despite the challenges, the preliminary results provide a much-needed glimpse of the spatial ecology of white-lipped peccaries in Belize. We present notes on behaviour, measurements of maximum and mean daily movement distances, habitat preference and home range estimates. We cautiously provide density and population size estimates, but future studies should focus on estimating peccary densities directly (e. g. via camera-trapping or genetic mark-recapture), assess variability of herd size in Belize, and collar a greater number of individuals. We note that the relocations of our herd are spread over BNR and all five surrounding protected areas, highlighting the necessity to coordinate management of these areas so as to avoid spill-over effects of disturbances from one area to the other. Improving the management of, and knowledge about, the white-lipped peccary populations in the Maya Mountains is crucial for their survival in Belize as well as for monitoring and maintaining the connectivity of the area to neighbouring forests of La Selva Maya and the Calakmul area (Reyna-Hurtado et al. 2009; Moreira-Ramírez et al. 2015).

\section{Acknowledgements}

M. Hofman was funded by the Erasmus Mundus Joint Doctoral Programme'Forest and Nature for Society' (FONASO). The protected area management team at the Ya'axché Conservation Trust have been instrumental for the entire field work component, as were the contribution of field equipment and advice from R. Foster and B. Harmsen from Panthera (Belizean chapter) and the Environmental Research Institute of the University of Belize, and the assistance from the Toledo Institute for Development and Environment for the transportation of trapping materials.

Supporting Information 1. Output of the home range calculations using rhr (Signer and Balkenhol 2015).

\section{Cited literature}

Aebischer, N., P. Robertson, and R. Kenward. 1993. Compositional analysis of habitat use from animal radio-tracking data. Ecology 74:1313-1325.

de Almeida Jácomo, A. T., M. M. Furtado, C. K. Kashivakura, J. Marinho-Filho, R. Sollmann, N. M. TôRRES, AND L. SILVEIRA. 2013. White-lipped peccary home-range size in a protected area and farmland in the central Brazilian grasslands. Journal of Mammalogy 94:137-145. 
Altrichter, M. 2005. The sustainability of subsistence hunting of peccaries in the Argentine Chaco. Biological Conservation 126:351-362.

Altrichter, M., A. Taber, H. Beck, R. Reyna-Hurtado, L. Lizarraga, A. Keuroghlian, and E. W. SAnderson. 2012. Range-wide declines of a key Neotropical ecosystem architect, the Near Threatened white-lipped peccary Tayassu pecari. Oryx 46:87-98.

Barlow, A. C. D. 2009. The Sundarbans tiger adaptation, population status, and conflict management. University of Minnesota, MN, USA.

BERDS. 2005. Biodiversity and Environmental Resource Data System. Belize Tropical Forest Studies. http://www.biodiversity.bz/.

Blake, S., I. Douglas-Hamilton, and W. B. Karesh. 2001. GPS telemetry of forest elephants in Central Africa: Results of a preliminary study. African Journal of Ecology 39:178-186.

Bodmer, R. E. 1990. Responses of ungulates to seasonal inundations in the Amazon floodplain. Journal of Tropical Ecology 6:191-201.

Brewer, S. W. S. And M. M. A. H. WebB. 2002. A seasonal evergreen forest in Belize: unusually high tree species richness for northern Central America. Botanical Journal of the Linnean Society 138:275-296.

Briggs, V. S., F. J. Mazzotti, R. G. Harvey, T. K. Barnes, R. Manzanero, J. C. Meerman, et al. 2013. Conceptual Ecological Model of the Chiquibul/Maya Mountain Massif, Belize. Human and Ecological Risk Assessment 19:317-340.

Byers, J. A., And M. Bekoff. 1981. Social, Spacing, and Cooperative Behavior of the Collared Peccary, Tayassu tajacu. Journal of Mammalogy 62:767-785.

Cain, J. W., P. R. Krausman, B. D. Jansen, and J. R. Morgart. 2005. Influence of topography and GPS fix interval on GPS collar performance. Wildlife Society Bulletin 33:926-934.

Campbell, K., J. Donlan, F. CRuz, and V. Carrion. 2004. Eradication of feral goats Capra hircus from Pinta Island, Galápagos, Ecuador. Oryx 38: 328-333.

Carrillo, E., J. C. J. Saenz, And T. K. Fuller. 2002. Movements and activities of white-lipped peccaries in Corcovado National Park, Costa Rica. Biological Conservation 108:317324.

Coelho, C. M., L. F. B. de Melo, M. A L. Sábato, D. N. Rizel, and R. J. Young. 2007. A note on the use of GPS collars to monitor wild maned wolves Chrysocyon brachyurus (Illiger 1815) (Mammalia, Canidae). Applied Animal Behaviour Science 105:259-264.

Cruz, F., V. Carrion, K. J. Campbell, C. Lavoie, C. J. Donlan. 2009. Bio-economics of large scale eradication of feral goats from Santiago Island, Galápagos. Journal of Wildlife Management 73:191-200

D'Eon, R.G. ANd D. Delparte. 2005. Effects of radio-collar position and orientation on GPS radio-collar performance, and the implications of PDOP in data screening. Journal of Applied Ecology 42:383-388.

Defra. 2003. Code of Recommendations for the Welfare of Livestock: Pigs. In Code of recommendations for the Welfare of Livestock. Department for Environment, Food and Rural Affairs, London, UK.

Desbiez, A.L.J., R .E. Bodmer, And S. A. Santos. 2009. Wildlife habitat selection and sustainable resources management in a Neotropical wetland. International Journal of Biodiversity and Conservation 1:11-20.

Desbiez, A. L. J., R. E. Bodmer, And W. M. Tomas. 2010. Mammalian Densities in a Neotropical Wetland Subject to Extreme Climatic Events. Biotropica 42:372-378.

Dourson, D. C. 2012. Biodiversity of the Maya Mountains, a focus on the Bladen Nature Reserve. Goatslug Publications, Bakersville, NC, USA. 
Edenius, L. 1996. Field test of a GPS location system for moose Alces alces under Scandinavian boreal conditions. Wildlife Biology 3:39-43.

Eriksen, A., P. Wabakken, B. Zimmermann, H. P. Andreassen, J. M. Arnemo, H. Gundersen, et al. 2011. Activity patterns of predator and prey: A simultaneous study of GPS-collared wolves and moose. Animal Behaviour 81:423-431Elsevier Ltd.

Fleming, C. H. and J. M. Calabrese. 2015. ctmm: Continuous-Time Movement Modeling. R package version 0.2.8.

Fleming, C. H., J. M. Calabrese, T. Mueller, K. a Olson, P. Leimgruber, and W. F. Fagan. 2014. From fine-scale foraging to home ranges: a semivariance approach to identifying movement modes across spatiotemporal scales. The American Naturalist 183:E154-E167.

Fragoso, J. M. V. 1998. Home Range and Movement Patterns of White-lipped Peccary (Tayassu pecari) Herds in the Northern Brazilian Amazon. Biotropica 30:458-469

Fragoso, J. M. V. 2004. A long-term study of white-lipped peccary (Tayassu pecari) population fluctuations in northern Amazonia - athropogenic versus'natural' causes. Pp. 286-296 in People in Nature: Wildlife Conservation in South and Central America. (eds K. Silvius, R. E. Bodmer \& J. M. V. Fragoso), Columbia University Press, New York, USA.

Fragoso, J. M. V. 1999. Perception of scale and resource partitioning by peccaries: behavioral causes and ecological implications. Journal of Mammalogy 80:993-1003.

Fuller, T., E. Carrillo, and J. Saenz. 2002. Survival of protected white-lipped peccaries in Costa Rica. Canadian Journal of Zoology 80:586-589.

Grandin, T. 2013. Recommended Animal Handling Guidelines \& Audit Guide: A Systematic Approach to Animal Welfare. American Meat Institute Foundation, Washington DC, USA.

Hammond, D., G. Busby, and R. Hartwell. 2011. Economic Valuation of the Environmental Goods and Services of the Maya Mountain Massif and the Maya Mountain Marine Corridor (Terrestrial Area). Ecosystem Economics, Bend, OR, USA.

Harju, S. M., C. V. Olson, M. R. Dzialak, J. P. Mudd, and J. B. Winstead. 2013. A flexible approach for assessing functional landscape connectivity, with application to greater sage-grouse (Centrocercus urophasianus). PLoS ONE 8.

Herrera, J.C.G. 2003. Mesoamerican Biological Corridor: regional initiative for the promotion of forest conservation. In Proceedings of the 12th World Forestry Congress. Food and Agriculture Organisation of the United Nations, Quebec City, Canada.

Hwang, M.-H., D. L. Garshelis, Y.-H. Wu, and Y. Wang. 2010. Home ranges of Asiatic black bears in the Central Mountains of Taiwan: Gauging whether a reserve is big enough. Ursus 21:81-96.

Iremonger, S., R. Liesner, ANd R. Sayre. 1995. Plant records from natural forest communities in the Bladen Nature Reserve, Maya Mountains, Belize. Caribbean Journal of Science 31:30-48.

IvLev, V. S. 1961. Experimental ecology of the feeding of fishes. Yale University Press, New Haven, CT, USA.

JACOBS, J. 1974. Quantitative measurement of food selection. Oecologia 14:413-417.

Johnson, D. 1980. The comparison of usage and availability measurements for evaluating resource preference. Ecology 61:65-71.

Kauhala, K. And M. Auttila. 2010. Estimating habitat selection of badgers - A test between different methods. Folia Zoologica 59:16-25.

Keuroghlian, A., and D. P. Eaton. 2008. Importance of rare habitats and riparian zones in a tropical forest fragment: preferential use by Tayassu pecari, a wide-ranging frugivore. Journal of Zoology 275:283-293. 
Keuroghlian, A., D.P. Eaton, and W.S. Longland. 2004. Area use by white-lipped and collared peccaries (Tayassu pecari and Tayassu tajacu) in a tropical forest fragment. Biological Conservation 120:411-425.

Kittie, R.A. And J. Terborgh. 1983. Observations on the Behavior of Rain Forest Peccaries in Perú: Why do White-lipped Peccaries Form Herds? Zeitschrift für Tierpsychologie 62:241-255.

Krofel, M., T. SKrbinšEK, AND I. Kos. 2013. Use of GPS location clusters analysis to study predation, feeding, and maternal behavior of the Eurasian lynx. Ecological Research 28:103-116.

Lizcano, D. J. and J. Cavelier. 2004. Using GPS Collars to Study Mountain Tapirs (Tapirus pinchaque) in the Central Andes of Colombia. Tapir Conservation 13:18-23.

Martins, Q., W. G. C. Horsnell, W. Titus, T. Rautenbach, and S. Harris. 2011. Diet determination of the Cape Mountain leopards using global positioning system location clusters and scat analysis. Journal of Zoology 283:81-87.

Matthews, A., L. Ruykys, B. Ellis, S. Fitzgibbon, D. Lunney, M. S. Crowther, et Al. 2013. The success of GPS collar deployments on mammals in Australia. Australian Mammalogy 35:65-83.

Meerman, J. C. 2007. Establishing a Baseline to Monitor Species and Key Biodiversity Areas in Belize. Belize Tropical Forest Studies, Belize, Central America.

Moen, R., J. Pastor, And Y. Cohen. 2001. Effects of animal activity on GPS telemetry location attempts. Alces 37:207-216.

Moreira-Ramírez, J. F., J. E. López, R. García-Anleu, F. Córdova, and T. Dubón. 2015. Tamaño, composición y patrones diarios de actividad de grupos de pecarí de labios blancos (Tayassu pecari) en el Parque Nacional Mirador-Río Azul, Guatemala. Therya 6:469-482.

Moreno, R. ANd N. Meyer. 2014. Distribution and conservation status of the White-lipped peccary (Tayassu pecari) in Panama. Suiform Soundings 13:32-35.

NietschmanN, B. 1972. Hunting and fishing focus among the Miskito Indians, eastern Nicaragua. Human Ecology 1:41-67.

Nogueira, S. S. D. C., I.K. Fernandes, T. S. O. Costa, S. L. G. Nogueira-Filho, and M. Mendl. 2015. Does Trapping Influence Decision-Making under Ambiguity in White-Lipped Peccary (Tayassu pecari)? Plos One 10:e0127868.

Phillips, K. A., C. R. Elvey, and C. L. Abercrombie. 1998. Applying GPS to the study of primate ecology: A useful tool? American Journal of Primatology 46:167-172.

Polmemus, D.A. and R. H. Carrie. 2013. A new species of Potamocoris (Heteroptera: Potamocoridae) from Belize, and synonymy of the genus Coleopterocoris. Tijdschrift voor Entomologie 156:141-149.

R Development Core Team. 2010. R: A language and environment for statistical computing. $R$ Foundation for Statistical Computing, Vienna, Austria.

Radachowsky, J., V. H. Ramos, R. McNab, E. H. Baur, and N. Kazakov. 2012. Forest concessions in the Maya Biosphere Reserve, Guatemala: A decade later. Forest Ecology and Management 268:18-28

Reyna-Hurtado, R. 2009. Conservation status of the white-lipped peccary (Tayassu pecari) outside the Calakmul Biosphere Reserve in Campeche, Mexico: a synthesis. Tropical Conservation Science 2:159-172.

Reyna-Hurtado, R., E. Rojas-Flores, and G. W. Tanner. 2009. Home range and habitat preferences of white-lipped peccaries (Tayassu pecari) in Calakmul, Campeche, Mexico. Journal of Mammalogy 90:1199-1209.

Reyna-Hurtado, R. and G. W. Tanner. 2005. Habitat preferences of ungulates in hunted and nonhunted areas in the Calakmul Forest, Campeche, Mexico. Biotropica 37:676-685. 
Sager-Fradkin, K. A., K. J. Jenkins, R. A. Hoffman, P. J. Happe, J. J. Beecham, and R. G. Wright. 2007. Fix Success and Accuracy of Global Positioning System Collars in Old-Growth Temperate Coniferous Forests. Journal of Wildlife Management 71:1298-1308.

Seaman, D. E. and R. A. Powell. 1990. Identifying patterns and intensity of home range use. Bears: Their Biology and Management 8:243-249.

Signer, J. And N. Balkenhol. 2015. Reproducible Home Ranges (rhr): A New, User-Friendly R Package for Analyses of Wildlife Telemetry Data. Wildlife Society Bulletin 39:358-363.

Sikes, R. S. And W. L. Gannon. 2011. Guidelines of the American Society of Mammalogists for the use of wild mammals in research. Journal of Mammalogy 92:235-253.

Sowls, L. K. 1997. Javelinas and Other Peccaries: Their Biology, Management, and Use. Texas A\&M University Press.

Sтотт, G. 2014. Vegetation monitoring in the Bladen Nature Reserve. Ya'axché Conservation Trust, Punta Gorda, Belize, Central America.

TayloR, D. And L. KatahiRa. 1988. Radio telemetry as an aid in eradicating remnant feral goats. Wildlife Society Bulletin 16:297-299

Thompson, F. G. And D. C. Dourson. 2013. A new land snail of the genus Eucalodium from Belize (Gastropoda: Pulmonata: Urocoptoidea: Eucalodiidae). The Nautilus 127:153155.

Tobler, M. W., S. E. Carrillo-Percastegui, and G. Powell. 2009. Habitat use, activity patterns and use of mineral licks by five species of ungulate in south-eastern Peru. Journal of Tropical Ecology 25:261-270.

Tomkiewicz, S. M., M. R. Fuller, J. G. KiE, AND K. K. Bates. 2010. Global positioning system and associated technologies in animal behaviour and ecological research. Philosophical transactions of the Royal Society ofLondon. Series B, Biological sciences 365:2163-2176.

Summited: October 1, 2015

Review: November 25, 2015

Accepted: January 15, 2016

Associated editor: Rafael Reyna

\section{Appendix 1: activity patterns}

Methods. From studies in Costa Rica, Peru and Guatemala, white-lipped peccaries are known to be diurnal animals with peak activity during mid-morning and midafternoon (Carrillo et al. 2002; Tobler et al. 2009; Moreira-Ramírez et al. 2015). We expected that white-lipped peccary activity patterns in Belize are similar to those observed elsewhere. We calculated step characteristics using the rhr package and compared movement rates (speed and distance) for different time periods during the day, using only time lags shorter than six hours.

Results. Speed and distance during different time periods during the day did not show the expected pattern of increased mobility during mid-morning and midafternoon activity peaks. However, no steps shorter than $6 \mathrm{hrs}$ were available for points with fix time of 9 am or 15 pm, while between two and seven were available for low-activity periods (Table A). This suggests that during the most active periods 
Table A. Diurnal variation in step length and speed.

\begin{tabular}{|c|c|c|c|c|c|c|c|c|c|}
\hline $\begin{array}{l}\text { Time of } \\
\text { day (h)* }\end{array}$ & $\mathbf{n}$ & $\begin{array}{l}\text { Max. } \\
\text { speed } \\
(\mathbf{k m} / \mathrm{h})\end{array}$ & $\begin{array}{l}\text { Mean } \\
\text { speed } \\
(\mathbf{k m} / \mathbf{h})\end{array}$ & $\begin{array}{c}\text { SD } \\
\text { speed } \\
(\mathbf{k m} / \mathbf{h})\end{array}$ & $\begin{array}{c}\text { Median } \\
\text { speed } \\
(\mathbf{k m} / \mathbf{h})\end{array}$ & $\begin{array}{l}\text { Max. } \\
\text { distance } \\
\text { (m) }\end{array}$ & $\begin{array}{c}\text { Mean } \\
\text { distance } \\
\text { (m) }\end{array}$ & $\begin{array}{c}\text { SD } \\
\text { distance } \\
\text { (m) }\end{array}$ & $\begin{array}{l}\text { Median } \\
\text { distance } \\
\text { (m) }\end{array}$ \\
\hline 00:00 & 2 & 0.08 & 0.06 & 0.03 & 0.06 & 224.97 & 172.19 & 74.64 & 172.19 \\
\hline 03:00 & 7 & 0.27 & 0.06 & 0.09 & 0.03 & 802.11 & 209.43 & 279.31 & 101.76 \\
\hline 06:00 & 3 & 0.09 & 0.05 & 0.04 & 0.03 & 277.85 & 138.00 & 123.03 & 89.72 \\
\hline 09:00 & 0 & - & - & - & - & - & - & - & - \\
\hline $12: 00$ & 1 & 0.07 & 0.07 & NA & 0.07 & 224.23 & 224.23 & NA & 224.23 \\
\hline 15:00 & 0 & - & - & - & - & - & - & - & - \\
\hline 18:00 & 1 & 0.04 & 0.04 & NA & 0.04 & 119.49 & 119.49 & NA & 119.49 \\
\hline 21:00 & 3 & 0.09 & 0.04 & 0.05 & 0.03 & 552.09 & 218.36 & 291.55 & 89.76 \\
\hline
\end{tabular}

*Time of day reflects the fix schedule programmed in the GPS-collar. Only steps with $\Delta t<6$ hours were included. 
no successful fixes were obtained, and thus no information on speed or distance is available for these critical times of the day. Therefore, we could not detect any significant signs of increased mobility during the expected activity peaks. 